\title{
Anatomical and physiological characteristics of leaves from Eugenia dysenterica DC. can predict nutritional deficiency symptoms
}

\author{
Layara Alexandre Bessa ${ }^{1}$, Luciana Cristina Vitorino ${ }^{1 *}$, Fabiano Guimarães Silva ${ }^{1}$, Sebastião de Carvalho \\ Vasconcelos Filho ${ }^{2}$
}

\author{
${ }^{1}$ Laboratory of Plant Mineral Nutrition; Instituto Federal Goiano (Goiano Federal Institute), Rio Verde campus, Rio \\ Verde - GO, Brazil \\ ${ }^{2}$ Laboratory of Plant Anatomy; Instituto Federal Goiano, Rio Verde campus, Rio Verde - GO, Brazil
}

\author{
*Corresponding Author: luciana.vitorino@ifgoiano.edu.br
}

\begin{abstract}
Plants receiving insufficient concentrations of the different essential nutrients may respond symptomatically to this stress. However, when the first visible symptoms of nutritional deficiency appear, plants already exhibit significant changes in their structure. As seedlings of $E$. dysenterica are important for the recovery of degraded areas and as the fruits of this species are widely exploited commercially, we decided to evaluate whether the omission of nutrients may affect the leaf anatomical ultrastructure, dry matter production and the synthesis of photosynthetic pigments in this plant, in an attempt to use data of this nature to predict symptoms of nutritional deficiency in seedlings of this species. For this purpose, we grow seedlings in a hydroponic system, offering all nutrients and also omitting each nutrient individually. Thus, we evaluated the effect of the omission of each nutrient on the anatomical leaf structure, dry mass production and the synthesis of photosynthetic pigments. Seedlings that grew in the absence of Ca and Mn exhibited compromised spongy parenchyma and mesophyll development, while the omission of $\mathrm{K}$ and $\mathrm{Mg}$ increased the number of epidermal cells and stomata. Low dry mass production in E. dysenterica was related to the omission of $\mathrm{S}$ and $\mathrm{Mn}, \mathrm{while} \mathrm{P}, \mathrm{N}$ and Fe deficiencies directly affected the synthesis of pigments. Thus, leaf anatomical and physiological data can predict nutritional deficiency conditions, enabling the user to diagnose the deficiency before the onset of symptoms in $E$. dysenterica seedlings. Our results may help investigators to understand the effects of nutritional omissions on other native Cerrado plants.
\end{abstract}

Keywords: Cagaita; hydroponic system; nutritional omission; macronutrients; micronutrients.

Introduction

Plants require calcium, magnesium, nitrogen, phosphorus, potassium and sulfur in relatively large amounts $(>0.1 \%$ of their dry mass) because these nutrients directly influence growth and development (Maathuis 2009). Plants receiving negligible concentrations of different essential nutrients may respond symptomatically, allowing us to use their response to adverse conditions to interpret their nutritional status (Bianco et al., 2015). The symptoms associated with mineral deficiencies are more or less characteristic for each element, although the severity of the response varies with the species/cultivar and environmental conditions (Wong, 2005). Thus, mineral nutrition allows for the establishment of an adequate level of each essential element for a given plant species and thus helps to determine the conditions required for maximum growth (Alvarenga et al., 2015) and the establishment of young plants in the field. It is important to note that symptoms of nutritional deficiency appear when plants are already under severe stress. Thus, using visual inspection to detect nutritional deficiency states for shortcycle plants, despite being recommended in some studies (e.g., de Almeida et al., 2017; Henry et al., 2018), is considered to be a late response. However, for perennial fruit plants, the detection of these symptoms is crucial for ensuring good crop development and yield, and for developing methods that may enable the detection of deficiencies before the onset of specific symptoms, i.e., before the worsening of the condition, which are required. Thus, because the physiological and anatomical effects of nutritional disorders appear before the visual symptoms in leaf tissues (Mattiello et al., 2015), we hypothesized that they could be used to predict nutritional deficiency states in E. dysenterica DC plants. Studies that address the effects of nutritional stress are usually focused on the damage caused to the overall nutrient balance and to growth in traditional crops (Santiago et al., 2018; Young et al., 2018; Aquino et al., 2019; da Silva et al., 2019). Studies on the adverse effects of nutritional stress usually do not evaluate anatomical effects, nor are they applied to native species, although they are essential for maintaining the native vegetation. Cagaita (E. dysenterica DC.), a species native to the Brazilian Cerrado (savannah), is important for the recovery of 
degraded areas as well as the commercial exploitation of fruits. The chemical composition and nutritional value of the fruits in this species have attracted attention from the native fruit market due to their levels of vitamins, minerals, phenolic compounds and antioxidants (Sousa et al., 2018). Moreover, because this plant is distributed throughout practically the whole Cerrado region, particularly the central region of the Cerrado, its seedlings have been used in forest restoration programs in this biome. Thus, many producers have focused on obtaining E. dysenterica seedlings, but the broad lack of knowledge about the nutritional requirements of this plant has made it difficult to obtain accessions capable of withstanding the adverse conditions in the field.

In the natural environment, plants are simultaneously exposed to many factors, such as changes in temperature and light intensity or even insufficient concentrations of macro- and micronutrients. Some of the adverse effects of nutrient deficiency stress on plants include low crop yield and quality, altered morphological structure (a smaller number of small xylem vessels) and widespread infestation by several diseases and pests (Malakouti, 2008). The first visible symptoms of this stress appear when plants already exhibit significant changes in the structure and functioning of the photosynthetic apparatus (Samborska et al., 2019), which modifies the anatomical and chemical structures of the leaf tissue. Therefore, methods that help to detect the first changes in the leaf ultrastructure can prevent production losses and increase the viability of the plant that will be established in the field because mitigating measures are required once stress conditions are observed. Thus, assuming that leaf tissue is widely sensitive to environmental changes, including nutrient deficiency, the aim of this study was to evaluate the effects of omitting different nutrients on the leaf anatomical ultrastructure, dry matter production and synthesis of photosynthetic pigments in E. dysenterica plants as well as to test the possibility of using anatomical and physiological data to predict cases of nutritional deficiency, enabling their diagnosis before the onset of symptoms.

\section{Results}

\section{Anatomical characteristics}

The omission of the micronutrients $\mathrm{N}$ or $\mathrm{S}$ affected the thickness of the adaxial epidermis in the $E$. dysenterica leaves, with mean thicknesses of 30.67 and $30.91 \mu \mathrm{m}$, respectively, although the average for plants grown in nutrient solution was slightly higher $(32.45 \mu \mathrm{m})$ (Figure 1a). However, the abaxial epidermis was not affected by the omission of any of the macronutrients tested here, and the mean adaxial epidermis thickness for all the treatments was $24.49 \mu \mathrm{m}$ (Figure 1b).

Regarding the parenchyma, the thickness of the palisade parenchyma was affected by $\mathrm{P}, \mathrm{Ca}$ or Mg deficiency, and the mean thicknesses observed in the plants grown under these treatments were 144.2, 144.3 and $131.5 \mu \mathrm{m}$, respectively, while in the plants grown in complete solution, the mean was $170.1 \mu \mathrm{m}$ (Figure 1c). The spongy parenchyma was more affected by the omission of $\mathrm{Ca}$ or $\mathrm{S}$, with mean thicknesses of 232.07 and $237.25 \mu \mathrm{m}$, while the mean observed for plants grown in complete solution was $337.4 \mu \mathrm{m}$ (Figure 1d). Similar to the pattern observed for the spongy parenchyma, the mesophyll thickness was also affected by the absence of $\mathrm{Ca}$ or
$S$ in the nutrient solution, such that the mean thickness values found in the absence of these nutrients were 390.43 and $378.84 \mu \mathrm{m}$, respectively (Figure 1e), and for plants grown in complete solution, it was $400.6 \mu \mathrm{m}$.

The results were slightly different when we analyzed the micronutrient omissions. The micronutrient absences did not directly affect the thickness of the adaxial or abaxial epidermis or the palisade parenchyma of $E$. dysenterica leaves, and the overall mean thicknesses obtained for these anatomical characteristics were 26.28, 33.08 and $157.76 \mu \mathrm{m}$ (Figure 2a-c).

The spongy parenchyma was, however, affected by the absence of all the tested nutrients, especially $B, Z n$ and $M n$, and the mean thicknesses observed for the plants grown under these treatments were 214.0, 214.3, and $187.2 \mu \mathrm{m}$, respectively (Figure $2 \mathrm{~d}$ ), while the mean found for plants grown in complete nutrient solution was $337.4 \mu \mathrm{m}$. Regarding the mesophyll, this tissue was primarily affected by the absence of $\mathrm{Mn}$, with a mean thickness of $327.7 \mu \mathrm{m}$, while plants grown in complete nutrient solution had a mean mesophyll thickness of $510.4 \mu \mathrm{m}$ (Figure 2e).

The negative effect of omitting $\mathrm{Ca}$ or $\mathrm{S}$ on the thickness of the spongy parenchyma and the mesophyll of $E$. dysenterica leaves can be observed by comparing the anatomical images obtained for the different macronutrient omission treatments (Figure 3). During the omission of the macronutrients $\mathrm{S}$ or $\mathrm{Mg}$, the production of epidermal cells was stimulated, such that means of 241.2 and 221.6 cells per $\mathrm{mm}^{-2}$, respectively, were observed in the leaves of plants grown in the absence of these elements (Figure 4a). However, stomata production was stimulated primarily by the omission of $\mathrm{K}$ or $\mathrm{Mg}$. The means were 84 and 81 stomata per $\mathrm{mm}^{-2}$, respectively (Figure $4 \mathrm{~b}$ ). For the stomatal index, a pattern similar to that observed for the number of stomata was observed, such that the highest mean was observed in the plants grown in the absence of $\mathrm{K}$, followed by the omission of $\mathrm{Mg}$, with values of $34.3 \%$ and $28.4 \%$, respectively (Figure $4 c$ ).

In general, the treatments involving micronutrient omissions affected the epidermal cells and stomata less than the macronutrient omissions, such that significant differences were observed only for the number of epidermal cells (Figure $4 \mathrm{~d}-\mathrm{f}$ ). The plants grown in the absence of $\mathrm{Fe}, \mathrm{Cu}$ and $\mathrm{B}$ showed reductions in the number of these cells, with means of 130 , 150 , and 146 cells per $\mathrm{mm}^{-2}$, respectively, while the mean obtained for the plants grown in complete solution was 156 cells per $\mathrm{mm}^{-2}$.

The positive effect of an increased number of epidermal cells compared to the control can be observed for the treatments that omitted the micronutrients S or $\mathrm{Mg}$ (Figure 5). It was also possible to observe an effective increase in the number of stomatal cells relative to the control treatment in plants grown in the absence of $\mathrm{K}$ or $\mathrm{Mg}$, while the effect of the omission of the micronutrients $\mathrm{Fe}, \mathrm{Cu}$ and $\mathrm{B}$ was negative for the overall number of epidermal cells (Figure 5).

\section{Dry mass evaluation}

The highest leaf dry mass values were observed in $E$. dysenterica plants grown in the absence of the macronutrients $\mathrm{K}$ and $\mathrm{N}$ ( 0.58 and $0.45 \mathrm{~g}$, respectively), and these values were similar to those observed in plants grown in complete nutrient solution ( $0.53 \mathrm{~g}$ ) (Figure 6a). The other omission treatments significantly affected the accumulation of biomass in these 
tissues, reducing the means to $0.13,0.25,0.32$ and $0.34 \mathrm{~g}$ in the treatments that omitted $\mathrm{S}, \mathrm{Ca}, \mathrm{Mg}$ and $\mathrm{P}$, respectively.

Regarding the stem dry mass, in general, all the macronutrient omission treatments affected biomass accumulation, although the worst responses were observed for plants grown in the absence of $\mathrm{N}$, which accumulated a mean of $0.10 \mathrm{~g}$ of dry mass on the stems (Figure 6b). However, the root dry mass was not affected by the absence of $\mathrm{N}$ or $\mathrm{Ca}$, so that plants grown in the absence of these nutrients accumulated averages of 0.47 and $0.44 \mathrm{~g}$ of root mass. These values were similar to those observed for plants grown in complete nutrient solution $(0.46$ g). The accumulation of root biomass, however, was primarily affected by the absence of $S$ from the solution because the roots of these plants accumulated only a mean of $0.24 \mathrm{~g}$ of root mass (Figure $6 \mathrm{c}$ ).

The total dry matter data followed a pattern similar to that observed for the leaf dry mass, and it was less affected by the absence of $\mathrm{N}$ or $\mathrm{K}$ than the other macronutrients. Thus, plants grown in the absence of $\mathrm{N}$ or $\mathrm{K}$ in the nutrient solution accumulated means of 1.03 and $1.10 \mathrm{~g}$ of total dry mass. However, the plants grown in the absence of $S$, similar to the observation for the root dry mass, exhibited the lowest overall dry matter accumulation $(0.71 \mathrm{~g}$ ) (Figure $6 \mathrm{~d}$ ).

The absence of the micronutrients $\mathrm{Fe}, \mathrm{Zn}$ or $\mathrm{Cu}$ did not affect the accumulation of dry mass in the leaves of $E$. dysenterica. The mean dry masses accumulated by plants grown in the absence of these nutrients were $0.48,0.54$ and $56 \mathrm{~g}$, respectively, similar to the mean observed for plants grown in complete solution $(0.54 \mathrm{~g})$. However, the lack of $\mathrm{Mn}, \mathrm{Mo}$ and $\mathrm{B}$ affected the dry mass of the leaves, such that means of 0.23 , 0.29 and $0.29 \mathrm{~g}$ were observed for plants grown in the absence of these nutrients, respectively (Figure 7a).

The effect of omitting the micronutrients on the stem dry mass was similar to that observed for the leaves, i.e., the omission of $\mathrm{Fe}, \mathrm{Zn}$ or $\mathrm{Cu}$ did not affect the accumulation of dry mass, and the means of these treatments $(0.24,0.21$ and $0.25 \mathrm{~g}$, respectively) were similar to that observed for plants grown in complete solution ( $0.23 \mathrm{~g}$ ) (Figure $7 \mathrm{~b})$. However, the stems of plants grown in the absence of B were more affected than those grown in the absence of other nutrients, with the mean dry mass being reduced to $0.13 \mathrm{~g}$. Regarding the dry mass of the roots, only the plants grown in the absence of $\mathrm{Zn}$ were unaffected, and the means observed for these plants and for those grown in complete solution were 0.56 and 0.47 , respectively. The highest root dry mass was observed in plants grown in the absence of $\mathrm{Mo}$ or $\mathrm{Mn}$, for which the means were 0.28 and $0.34 \mathrm{~g}$ (Figure 7c).

When analyzing total dry mass, we also found an effect similar to that observed for leaves. In general, the absence of the micronutrients $\mathrm{Fe}, \mathrm{Zn}$ or $\mathrm{Cu}$ did not affect the total biomass accumulation. The observed means for these treatments were $1.13,1.31$ and $1.25 \mathrm{~g}$, and for plants that grew in complete solution, the mean was $1.23 \mathrm{~g}$. However, the lack of Mn, Mo and $B$ affected the total dry mass, reducing the means to 0.72 , 0.74 and 0.87 (Figure $7 d$ ).

\section{Chloroplast pigment concentration}

The levels of chlorophyll a in the $E$. dysenterica seedlings were primarily affected by the absence of $P$ in the solution, with a mean concentration of $2.54 \mu \mathrm{g} \mathrm{mL}^{-1}$ of this pigment in the leaves subjected to this treatment (Figure 8a). However, the chlorophyll a concentration was also affected in plants grown in the absence of $\mathrm{N}$, with $3.44 \mu \mathrm{g} \mathrm{mL}^{-1}$ being the mean for this treatment. The chlorophyll $\mathrm{b}$ content was also affected by the omission of $\mathrm{N}$, and the mean concentration of this pigment observed in the plants was $1.81 \mu \mathrm{g} \mathrm{mL}^{-1}$ (Figure $8 \mathrm{~b}$ ). Similar to that observed for chlorophyll a, the total chlorophyll was also primarily affected by the absence of $\mathrm{P}$, followed by the omission of $\mathrm{N}$, and the mean total chlorophyll concentrations for these treatments were 4.82 and $5.10 \mu \mathrm{g} \mathrm{mL}^{-1}$, respectively (Figure 8c). The concentrations of carotenoids followed a similar pattern to that of chlorophyll $b$, with its levels primarily being affected by $\mathrm{N}$, followed by $\mathrm{S}$ and $\mathrm{K}$, with mean values of $1.48,1.58$ and $1.60 \mu \mathrm{g} \mathrm{mL}^{-1}$, respectively (Figure $8 \mathrm{~d}$ ).

The absence of micronutrients in the nutrient solution also differentially affected the synthesis of pigments by $E$. dysenterica leaves, and the chlorophyll a concentration was primarily affected by the omission of Fe; the mean observed for this pigment in plants grown in the absence of this micronutrient was $1.89 \mu \mathrm{g} \mathrm{mL}^{-1}$ (Figure 9a). Similar behavior was observed for chlorophyll $b$, for which the lowest means were observed for plants grown in the absence of Fe but also for plants grown in the absence of Mo. A mean value of 1.94 $\mu \mathrm{g} \mathrm{mL}{ }^{-1}$ was observed in both cases (Figure 9b). The absence of Fe also affected the production of total chlorophyll and carotenoids. In general, the plants behaved similarly in relation to these two pigments in the different treatments. The observed means were 3.42 and $1.14 \mu \mathrm{g} \mathrm{mL-}{ }^{1}$ for the total chlorophyll and carotenoids, respectively (Figure $9 \mathrm{c}$ and d).

\section{Discussion}

\section{Anatomical characteristics}

Our study confirms the differential effect of nutrients on the development of the leaf morpho-anatomical structures in $E$. dysenterica. This effect was also confirmed for another species native to the Cerrado, Anacardium othonianum Rizz, for which different $\mathrm{N}$ concentrations were found to alter the densities of the epidermal and parenchymal cells (Bessa et al., 2017). In this study, the omission of $\mathrm{N}$ negatively affected only the adaxial epidermis of $E$. dysenterica, and the anatomical structures of this plant were more sensitive to the omission of $\mathrm{Ca}$, which hindered the development of spongy parenchyma and mesophyll. This result occurs because extracellular $\mathrm{Ca}^{2+}$ plays a crucial role in maintaining the integrity of the plasma membrane (Orlov et al., 2005), which is important for the formation of leaf anatomical structures. Therefore, this nutrient helps confer tolerance to biotic stresses, such as parasitic diseases, because it reinforces the cell walls, making them resistant to attacks by pathogens (White and Broadley, 2003). Coca and San Segundo (2010) showed that a calciumdependent protein kinase (CPK) mediates resistance to pathogens in Arabidopsis, and it is rapidly induced by fungal elicitors. The $\mathrm{Ca}^{2+}$ ion also plays a crucial role as a mediator in the regulation and specification of cellular responses to environmental stresses (Dodd et al., 2010; Choi et al., 2016; Ranty et al., 2016). In the absence of this ion, plants become more sensitive to environmental stresses and could develop symptoms more quickly because resistance pathways such as those associated with salicylic acid are less frequently expressed (Wang et al., 2009). In the present study, the 
omission of calcium was a true nutritional stress, and it directly affected the formation of the anatomical structures.

The micronutrient omission that most affected the morphoanatomical development was the omission of $\mathrm{Mn}$. The spongy parenchyma and mesophyll were underdeveloped under $\mathrm{Mn}$ lacking conditions, which may be related to the important role of $\mathrm{Mn}$ in the protein structure and in the activation of important enzymes during the photosynthetic process. We believe that the absence of this micronutrient affected photosynthesis and consequently the development of the parenchyma and mesophyll. The absence of this nutrient can affect the leaf structure by causing chloroplast damage, affecting water photolysis in photosystem II, which provides the electrons necessary for photosynthesis. Roosta et al. (2017) observed that in lettuce leaves, the absence of $\mathrm{Mn}$ negatively affects chlorophyll fluorescence, quantum yield and specific energy fluxes. In fact, a chain of altered physiological events can culminate in subcellular changes that lead to epidermal changes (Junior et al., 2010).

We found a positive response in the number of epidermal cells and stomata in the absence of the macronutrient $\mathrm{Mg}$. The absence of $\mathrm{K}$ also stimulated the synthesis of stomata and an increase in the stomatal index. The stomata represent a point of entry and exit for water, and thus, increases in the stomatal index represent a possible attempt by the plant to adapt to nutritional stress. The $\mathrm{Mg}$ ion is involved in the antioxidative metabolism of plants, in the activation of some enzymes, and, together with $\mathrm{N}$, it is required for the synthesis of chlorophyll (Keunen et al., 2011), so the plant interprets a photosynthetic deficiency as a low influx of $\mathrm{CO}_{2}$, increasing the number of epidermal stomata.

\section{Dry mass evaluation}

E. dysenterica plants were very sensitive to the omission of $\mathrm{S}$, such that the leaf, root and total dry masses were affected by the omission of this macronutrient. Miranda et al. (2017) worked with Brachiaria Convert and found that the omission of $S$ might reduce the dry mass. Tsujimoto et al. (2013) also concluded that $\mathrm{S}$ deficiency inherently reduces dry mass production in rice. Moreover, Almeida et al. (2014) showed that $S$ is one of the nutrients that is most required by Zantedeschia aethiopica seedlings grown in nutrient solution. In fact, sulfur plays a crucial role in the structure and functioning of proteins, the redox status and the biotic stress response of plants (Gläser et al., 2014). Sulfur deprivation may have profound effects on nitrogen nutrition and on plant responses to oxidative stress, which will affect the plant growth, quality and yield (Hirai et al., 2004; Nikiforova et al., 2005).

Regarding micronutrients, the absence of $\mathrm{Mn}, \mathrm{Mo}$ or $\mathrm{B}$ significantly affected the accumulation of biomass in $E$. dysenterica plants. These data are in agreement with the morpho-anatomical indices, which were strongly affected by the absence of $\mathrm{Mn}$. Studies have shown that manganese deficiency is a common micronutrient deficiency in important crops, such as soybeans (Sutradhar et al., 2017), and these crops respond well to the application of micronutrients such as $\mathrm{Mn}, \mathrm{B}, \mathrm{Cl}$ and $\mathrm{Zn}$. Similarly, B causes nutritional problems because it is seldom available in tropical soils (de Souza et al., 2015), such as in the Cerrado biome. We have already highlighted the importance of $\mathrm{Mn}$ in photosynthetic processes, but $\mathrm{Mn}$ is also a constituent of manganese superoxide dismutase (MnSOD), the primary antioxidant defense enzyme in the mitochondria (Socha and Guerinot ,2014; Shen, 2015). $\mathrm{Mn}$ acts as a cofactor or activator for a number of enzymes that regulate the catalysis of oxidation, reduction, decarboxylation and hydrolytic reactions (Marschner, 2012). The unavailability of these micronutrients can therefore be a real problem for the $E$. dysenterica crop.

\section{Photosynthetic pigments}

In $E$. dysenterica seedlings, the omission of $\mathrm{P}$ limited the production of chlorophyll a and total chlorophyll; however, unlike the results observed here, $\mathrm{P}$ was the macronutrient that least affected the production of photosynthetic pigments in Salvia hispanica L. (Dos Anjos et al., 2018). For that species, N was the macronutrient that most affected the synthesis of pigments. We also observed the effect of the absence of $\mathrm{N}$ on photosynthetic pigment synthesis, especially for chlorophyll $b$ and carotenoids. In Achillea millefolium L. plants, the omission of $\mathrm{N}$ from the hydroponic culture also reduced the levels of carotenoids $\left(0.15 \mu \mathrm{g} \mathrm{mL} \mathrm{m}^{-1}\right.$ ) (Alvarenga et al., 2015), and in sweet potatoes, $\mathrm{N}$ and $\mathrm{P}$ deficiencies severely affect the chlorophyll concentration (Siose et al., 2017), thus compromising the photosynthetic activity of the plant. The absence of these nutrients also affected the vegetative development of sweet potatoes, given that phosphorus is vital for most physiological processes in plants (see Mia, 2015).

The absence of the micronutrients $\mathrm{Zn}$ or B did not limit the synthesis of chlorophyll a and total chlorophyll in $E$. dysenterica seedlings, showing that these ions may not be essential during the early stages of leaf tissue development in this plant. In Achillea millefolium L. plants, the absence of $\mathrm{Zn}$ also affected the synthesis of total chlorophyll $\left(0.91 \mu \mathrm{g} \mathrm{mL}^{-1}\right)$ (Alvarenga et al., 2015), which was affected by the absence of the micronutrient Fe $(0.22 \mu \mathrm{g} \mathrm{mL}-1)$, similar to the finding observed for cagaita plants. In Jatropha curcas L. plants, the chlorophyll content as well as the photosynthetic index were also more affected by the absence of Fe than the other micronutrients (Santos et al. 2013). In plant cells, the importance of Fe for the photosynthetic process is so great that chloroplasts constitute the largest iron deposits in the cells (Divol et al., 2013). Osório et al. (2014) showed that in strawberry plants (Fragaria $\times$ ananassa Duch. Cv 'Diamond'), the total chlorophyll concentration in young leaves decreased progressively over time in plants grown in solution without Fe, such that the chlorophyll fluorescence can be used to evaluate nutritional problems associated with iron. We also found that for $E$. dysenterica plants, low chlorophyll concentrations might be associated with $\mathrm{N}, \mathrm{P}$ and Fe deficiencies.

In general, we found that the morpho-anatomical and physiological structures of E. dysenterica are affected by nutrient deficiencies, and it is possible that anatomical sections or measurements of photosynthetic pigment concentrations can be used to identify nutritional problems prior to the onset of visual symptoms of deficiencies. Histological section analyses are currently conducted, and they require special devices such as dyes and microscopes; however, the production of pigments in leaves can easily be inferred using low-cost equipment such as a portable chlorophyll meter, SPAD and/or Dualex. These analyses would have a high costbenefit ratio and might anticipate deficiency symptoms in $E$. 


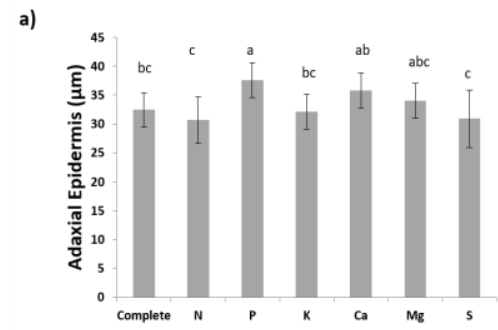

b)
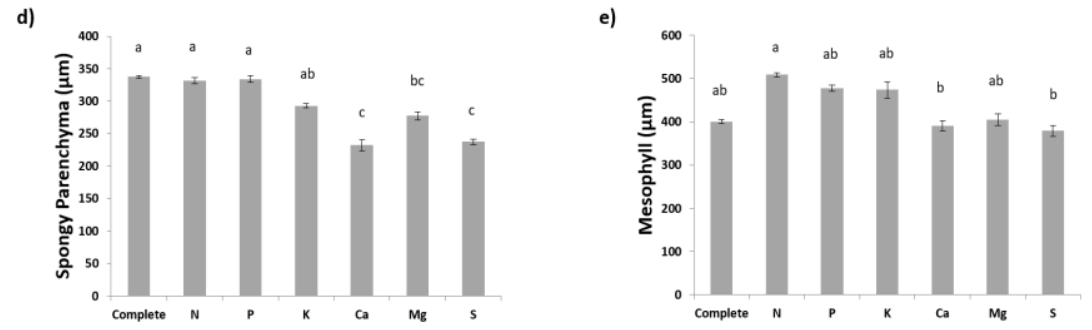

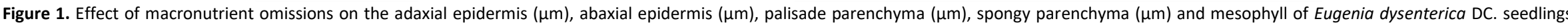
grown in a hydroponic system with complete nutrient solution and in solutions omitting $\mathrm{N}, \mathrm{P}, \mathrm{K}, \mathrm{Ca}, \mathrm{Mg}$ or $\mathrm{S}$. The data were collected 120 days after transplanting.

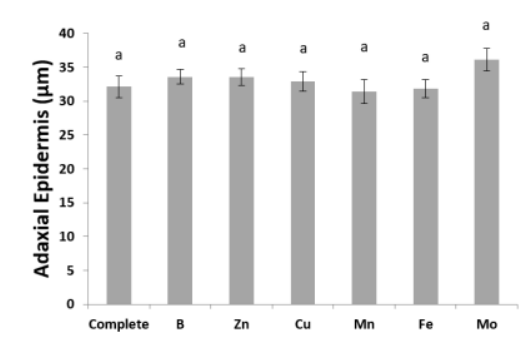

b)

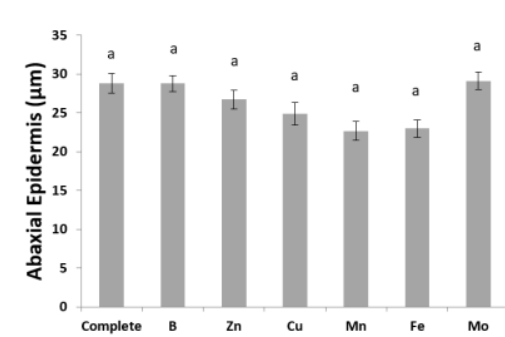

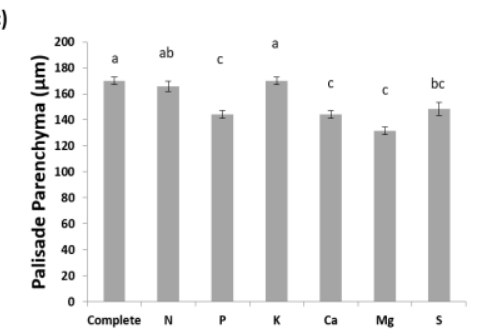

d)

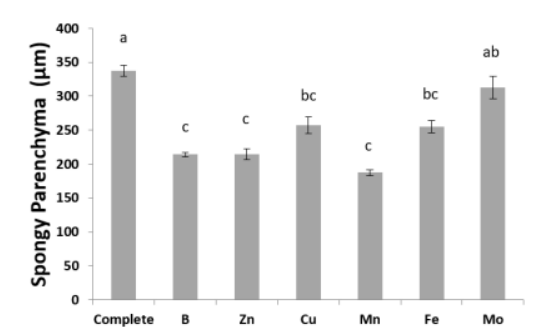

c)

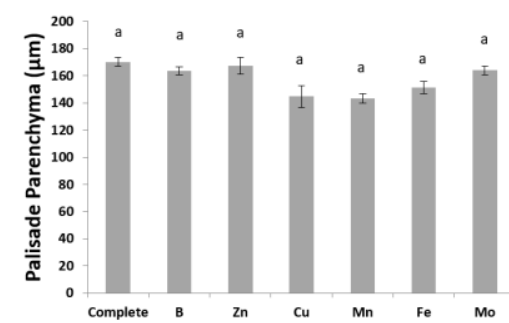

e)

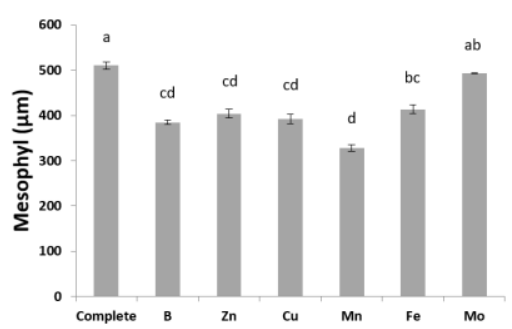

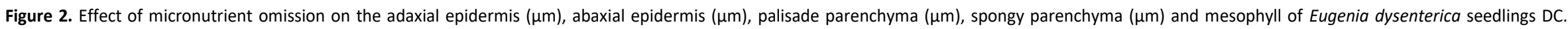
grown in a hydroponic system with complete nutrient solution and without $\mathrm{B}, \mathrm{Zn}, \mathrm{Cu}, \mathrm{Mn}$, Fe or Mo. The data were taken 120 days after transplanting. 


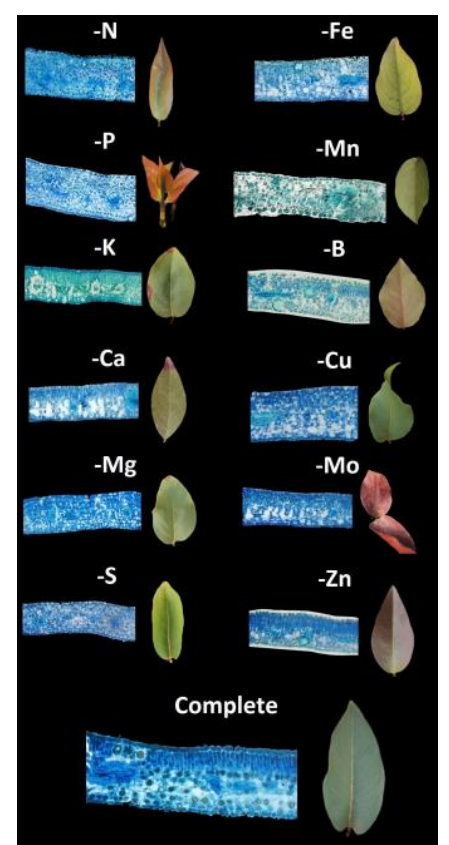

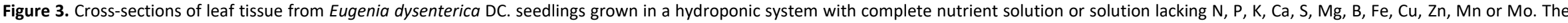
data were collected 120 days after transplanting and were obtained by staining with toluidine blue.

a)
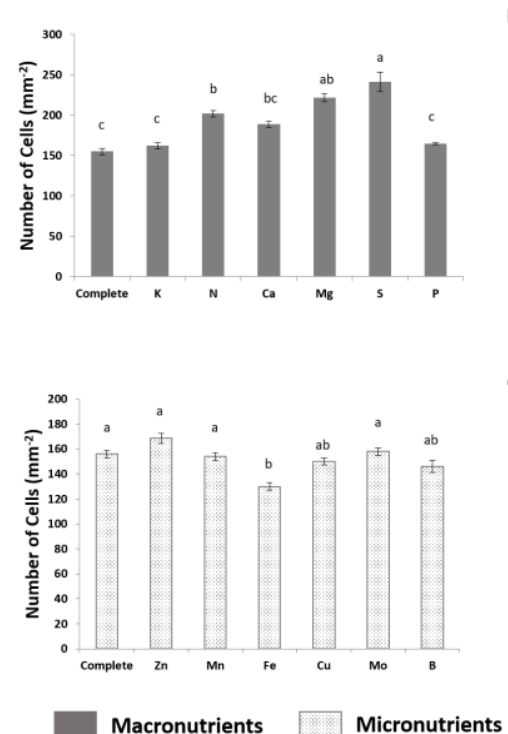
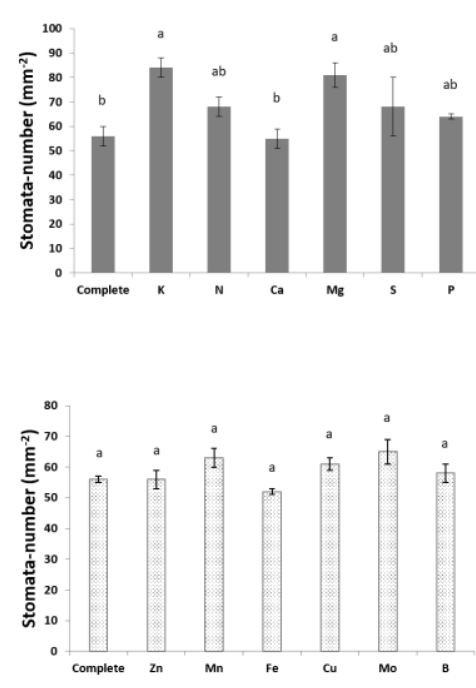
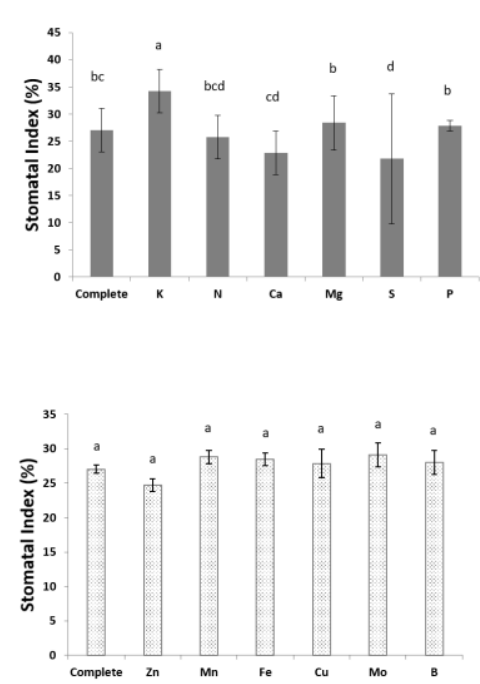

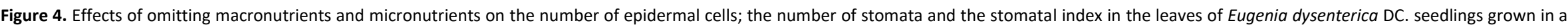
hydroponic system with complete nutrient solution and without $\mathrm{N}, \mathrm{P}, \mathrm{K}, \mathrm{Ca}, \mathrm{S}, \mathrm{Mg}, \mathrm{B}, \mathrm{Fe}, \mathrm{Cu}, \mathrm{Zn}, \mathrm{Mn}$ or Mo. The data were collected 120 days after transplanting. 


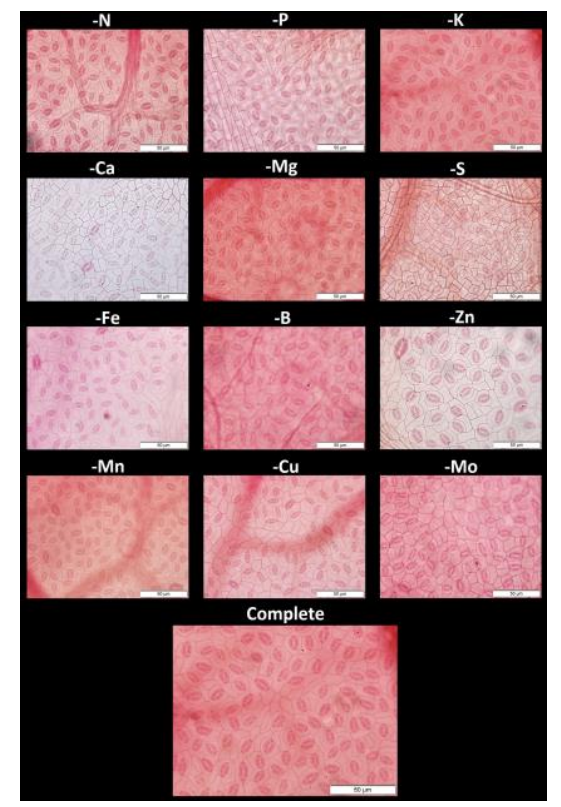

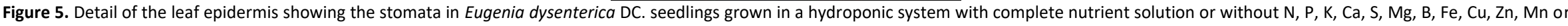
Mo. The data were observed 120 days after transplanting.

a)
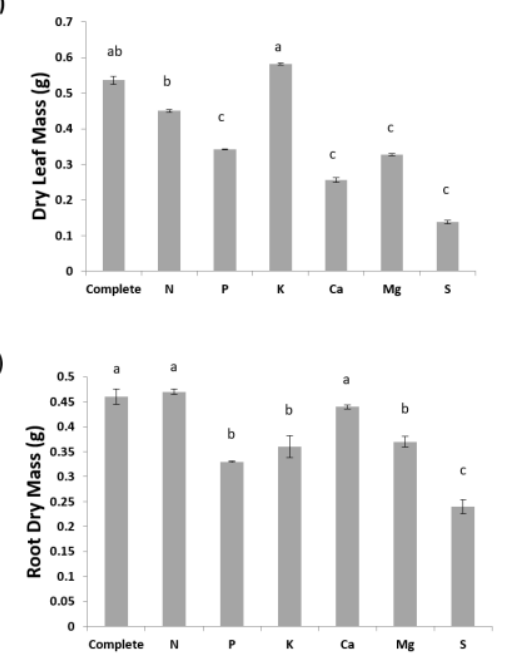

b)

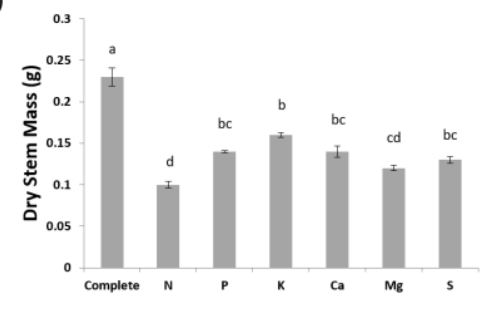

d)

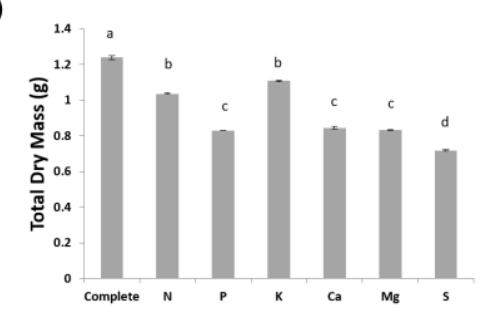

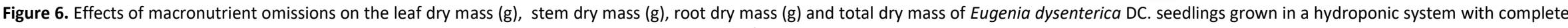
nutrient solution and in solution omitting $\mathrm{N}, \mathrm{P}, \mathrm{K}, \mathrm{Ca}, \mathrm{Mg}$ or $\mathrm{S}$. The data were collected at 120 days after transplanting. 
a)
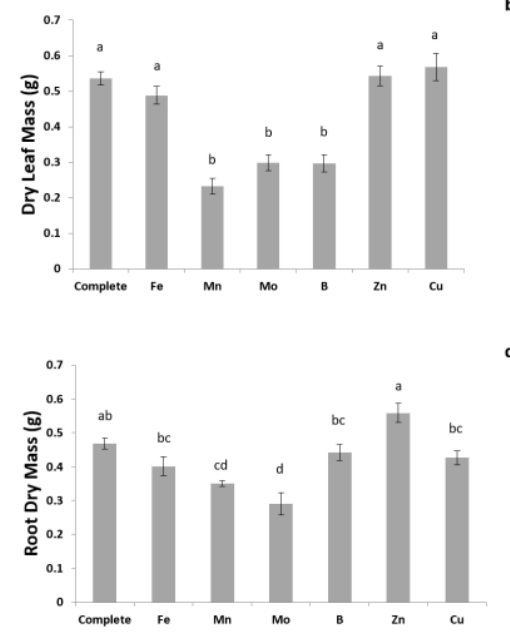

b)
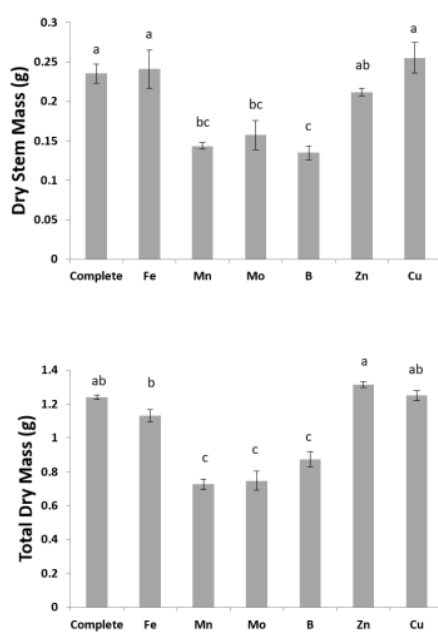

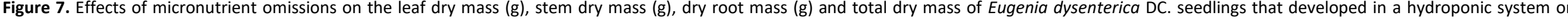
complete nutrient solution or in solutions lacking B, $\mathrm{Cu}, \mathrm{Fe}, \mathrm{Mn}, \mathrm{Mo}$ or $\mathrm{Zn}$. The data were collected 120 days after transplanting.

a)
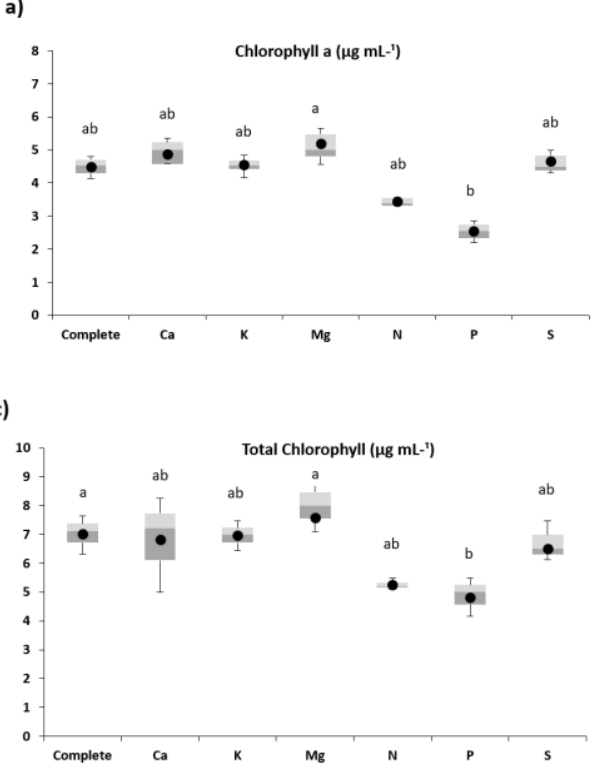

b)
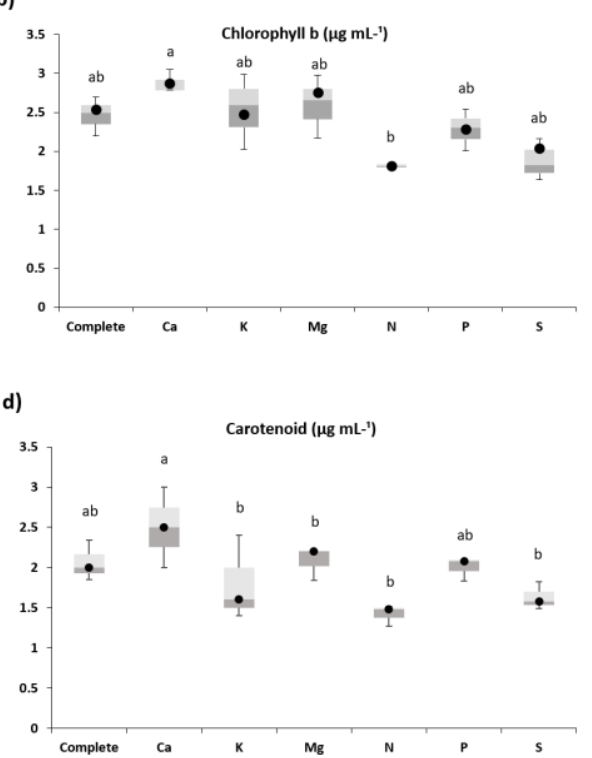

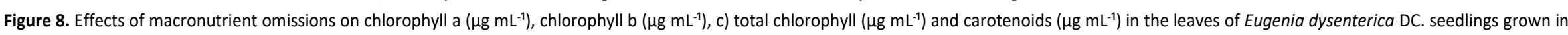
a hydroponic system with complete nutrient solution or in solutions lacking $\mathrm{N}, \mathrm{P}, \mathrm{K}, \mathrm{Ca}, \mathrm{Mg}$ or $\mathrm{S}$. The data were recorded at 120 days after transplanting. 

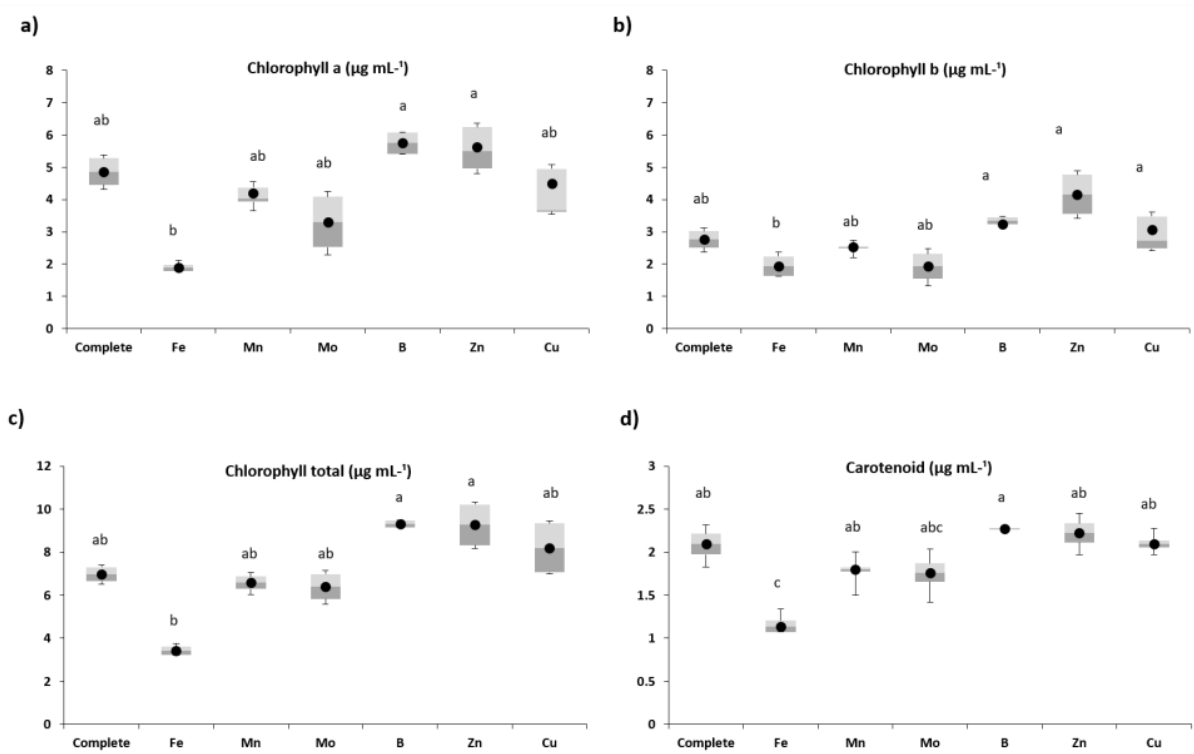

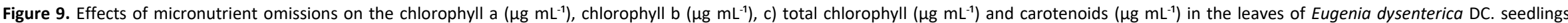
grown in a hydroponic system with complete nutrient solution and solution without $\mathrm{B}, \mathrm{Cu}, \mathrm{Fe}, \mathrm{Mn}, \mathrm{Mo}$ or $\mathrm{Zn}$. The data were collected 120 days after transplanting

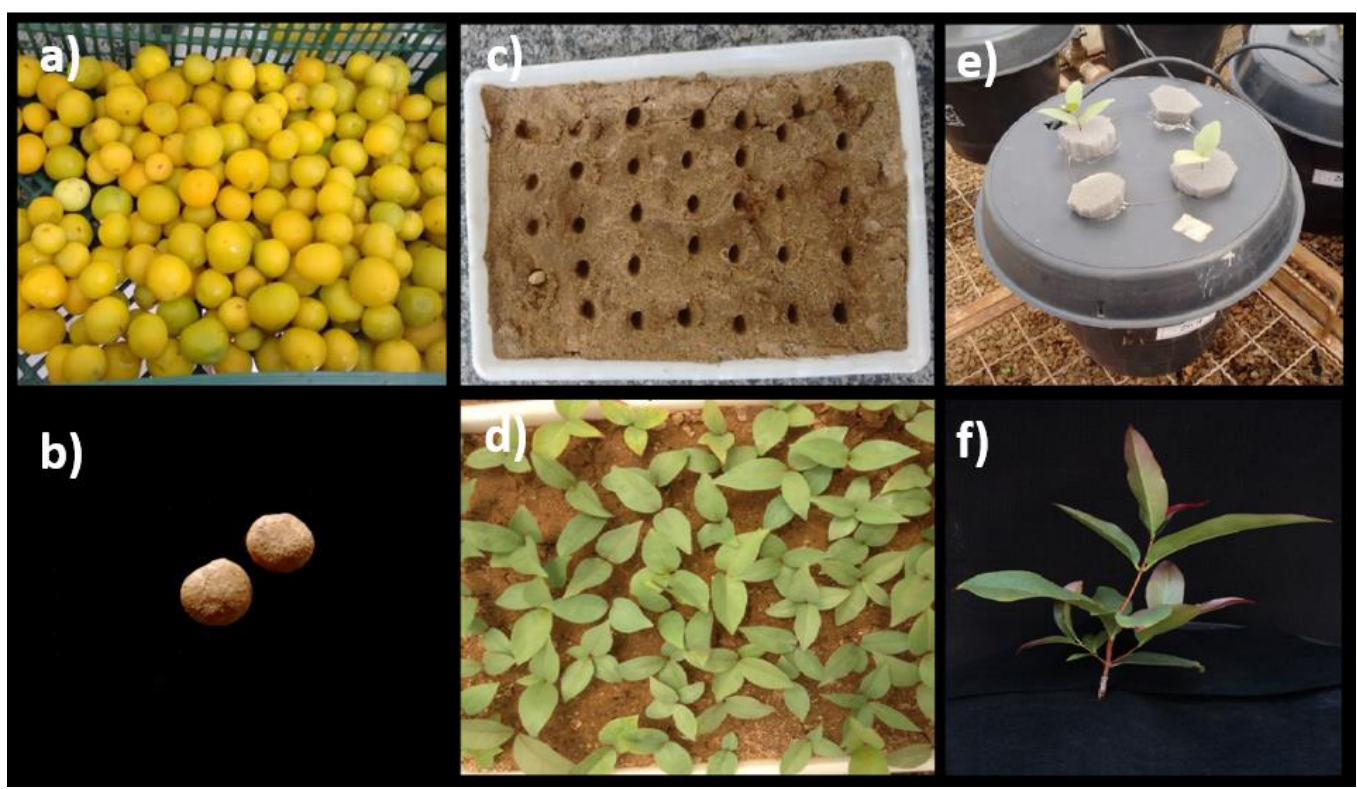

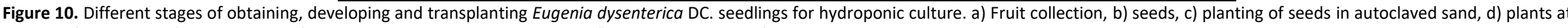
30 days after sowing, e) transplanting of seedlings into hydroponic culture and f) plants at 120 days after transplanting. 
dysenterica. Through this study, we hope to promote the analysis of morpho-anatomical and physiological changes associated with nutritional deficiencies in other species so that management measures can be implemented through the use of these data.

\section{Materials and Methods}

\section{Collection and growth of seedlings}

The experiments were conducted in the city of Rio Verde $\left(17^{\circ} 48^{\prime} 16^{\prime \prime} \mathrm{S}, 50^{\circ} 54^{\prime} 19^{\prime \prime} \mathrm{W}\right.$ at $749 \mathrm{~m}$ altitude) in the center-west region of Brazil between the months of November 2015 and June 2016. The seedlings used here were obtained by germinating $E$. dysenterica DC. seeds in plastic trays containing autoclaved sand as a substrate. At 30 days after sowing, the seedlings were transferred to hydroponic culture pots (Figure 10). The seeds were obtained from ripe fruits that were collected from a single native mother tree at Gameleira Farm, which is located in the municipality of Montes Claros de Goiás, in the state of Goiás, or GO $\left(16^{\circ} 06^{\prime} 20^{\prime \prime} \mathrm{S}\right.$ and $51^{\circ} 17^{\prime} 11^{\prime \prime} \mathrm{W}$ at $592 \mathrm{~m}$ of altitude).

A hydroponic culture was set up using an aerated system in 8liter plastic pots in a greenhouse. During the first 30 days of hydroponic culture, the seedlings were grown in half-strength Hoagland's nutrient solution (Hoagland and Arnon 1950). After this adaptation period, the solutions were replaced with treatments consisting of the complete solution and individual omission of macro and micronutrients ( $\mathrm{N}, \mathrm{P}, \mathrm{K}, \mathrm{Ca}, \mathrm{Mg}, \mathrm{S}, \mathrm{B}, \mathrm{Cu}$, $\mathrm{Fe}, \mathrm{Mn}, \mathrm{Zn}$ or Mo).

\section{Anatomical characteristics}

These characteristics were evaluated at 120 days after transplanting (DAT). For this purpose, $0.5 \mathrm{~cm}^{2}$ samples were collected from the middle third of the leaves of one plant per pot using disposable razors. The samples were then fixed in Karnovsky's (1965) solution for 24 hours, dehydrated in a graded ethanol series, and pre-embedded and embedded in historesin (Historesin-Leica) according to the manufacturer's recommendations. The material was cross-sectioned to a $5-\mu \mathrm{m}$ thickness in a rotary microtome (Model 1508R). The sections were subsequently stained with $0.05 \%$ toluidine bluepolychromatic staining in $0.1 \mathrm{M}$ phosphate buffer, $\mathrm{pH} 6.8$ for structural analysis and micromorphometric analysis (O'Brien et al., 1964). The variables analyzed here were the thickness of the adaxial and abaxial epidermis, the palisade and spongy parenchyma, the mesophyll, and the areas stained with phenolic compounds and alkaloids, which were obtained with the image processing tool ImageJ (Open source code, http://rsbweb.nih.gov/ij/download.html) (Ferreira and Rasband, 2010).

To determine the stomatal index and stomatal density (stomata $\mathrm{mm}^{-2}$ ), 30 observations were performed per plant on each epidermal surface in image fields with an area of 0.067 $\mathrm{mm}^{2}$, and these indices were estimated using Image-Pro Plus 4.5 software (Media Cybernetics, Silver Spring, USA). The stomatal index was determined according to the following formula: Stomatal Index $(\mathrm{SI})=\mathrm{NS} /(\mathrm{EC}+\mathrm{NS})$, where NS is the number of stomata and EC is the number of epidermal cells (Cutter 1986).

Leaf tissue samples were also subjected to the clearing process proposed by Arnott (1959) and modified by Lersten (1967) to visualize the surface of the epidermis.

\section{Dry mass evaluation}

At 120 DAT, the plants were separated into roots, stems and leaves and dried in a forced air oven at $65^{\circ} \mathrm{C}$ until reaching a constant weight to determine the dry mass. Subsequently, the material was weighed and the leaf (LDM), stem (SDM), root (RDM) and total dry masses (TDM) were obtained, and the TDM was the sum of the previous dry masses.

\section{Chloroplast pigment concentration}

The concentrations of chlorophyll $a$ and $b$ and the carotenoid pigments were determined using the methodology described by Costa et al. (2014). The absorbance of the extract was then determined in an Evolution 60S UV-VIS spectrophotometer (Thermo Fisher Scientific, WI, USA). Pigment quantification was performed as proposed by Wellburn (1994).

\section{Statistical analysis}

The morpho-anatomical and physiological data were obtained from plants with no visual symptoms of nutritional deficiency. The experiment was conducted in a randomized block design, with 4 replicates per treatment. Each pot was considered an experimental unit consisting of two plants per pot. Twelve nutrient suppression treatments $(\mathrm{N}, \mathrm{P}, \mathrm{K}, \mathrm{Ca}, \mathrm{Mg}, \mathrm{S}, \mathrm{B}, \mathrm{Cu}, \mathrm{Fe}$, $\mathrm{Mn}, \mathrm{Zn}$ or $\mathrm{Mo}$ ) and a control treatment (plants grown in complete nutrient solution) were evaluated. These treatment solutions were provided to the plants at full ionic strength, given by Hoagland's nutrient solution, throughout the growing period.

The results for the anatomical characteristics (adaxial and abaxial epidermis, palisade parenchyma, spongy parenchyma and mesophyll, number of epidermal cells, number of stomata and stomatal index) were obtained from 10 observations per repetition. The data were analyzed by one-way ANOVA and the means were subsequently compared using Tukey's test at a $5 \%$ probability. The dry mass results and the concentrations of the chlorophyll a, chlorophyll b, total chlorophyll and carotenoids were obtained separately for all the plants, and the value for each experimental unit was calculated as the average of the observations for the two plants in the unit. These data were also analyzed by one-way ANOVA and compared by Tukey's test at $5 \%$ probability. Statistical analyses were performed using SISVAR software (Ferreira, 2010).

\section{Conclusion}

The omission of different nutrients differentially affects the leaf anatomical ultrastructure, dry mass production and synthesis of photosynthetic pigments in E. dysenterica plants. Thus, the absence of $\mathrm{Ca}$ and $\mathrm{Mn}$ can be identified via adverse effects on spongy parenchyma and mesophyll; the omission of $\mathrm{K}$ and $\mathrm{Mg}$ promotes the formation of a large number of epidermal cells and stomata. Low dry matter production in $E$. dysenterica may indicate $\mathrm{S}$ or Mn deficiency, while $\mathrm{P}, \mathrm{N}$ or Fe deficiency directly affect the synthesis of pigments. We confirmed the hypothesis that anatomical and physiological data can be used to predict cases of nutritional deficiency, enabling its diagnoses before the onset of symptoms in $E$. dysenterica seedlings. More broadly, the results found here may help to predict the harmful effects of stress caused by the 
omission of nutrients from cagaita and to understand these same effects in other native plants.

\section{Acknowledgements}

The authors are grateful to the Fundação de Amparo à Pesquisa do Estado de Goiás (Goiás Research Foundation, FAPEG) and the IFGoiano, Rio Verde Campus for the infrastructure and for the students involved in this study.

\section{Disclosure statement}

No potential conflict of interest was reported by the authors.

\section{Orcid}

Layara A. Bessa https://orcid.org/0000-0001-6286-9260

Luciana C. Vitorino https://orcid.org/0000-0001-7271-9573

Sebastião C. Vasconcelos Filho https://orcid.org/0000-00022061-7062

\section{References}

Anjos GL, Costa FM, Lobo CQ, Souza AA, Souza GS, Santos AR (2018) Growth and photosynthetic pigment content in Salvia hispanica L. with macronutrient omission in nutrient solution. Científica. 46:323-328.

Almeida EFA, Paiva PDO, Carvalho JG, Frazão JEM, Oliveira NP (2014) Descriptive analyses of deficiency symptoms in calla lily plants. Journal of Plant Nut. 38:160-172.

Almeida TBF, Flores RA, Almeida HJ, Prado RM, Maranhão DDC, Politi LS (2017) Development and nutrition of soybeans with macronutrients deficiencies. Commun Soil Sci Plan. 48:1616-1625.

Alvarenga IC, Boldrin PF, Pacheco FV, Silva ST, Bertolocci SKV, Pinto JEBP (2015) Effects on growth, essential oil content and composition of the volatile fraction of Achillea millefolium $\mathrm{L}$. cultivated in hydroponic systems deficient in macro- and microelementos. Sci Hortic. 197:329-338.

Arnott HJ (1959) Leaf clearing. Turtox News. 37:192-194.

Baset Mia MA (2015) Nutrition of crop plants - Plant science, research and practices. pp 69-74. (Nova Science Publisher, Inc. NY)

Bessa LA, Moreira MA, Silva FG, Vitorino LC, Rodrigues CL, Vasconcelos Filho S (2017) Morphoanatomical characteristics of leaves of Anacardium othonianum Rizz. seedlings subjected to different nitrogen doses under hydroponic conditions. Aust J Bot. 665:524-537.

Bianco MS, Cecílio Filho AB, Carvalho LB (2015) Nutritional status of the cauliflower cultivar 'Verona' grown with omission of out added macronutrients. PLoS One. 10:e0123500.

Choi W-G, Hilleary R, Swanson SJ, Kim S-H, Gilroy S (2016) Rapid, long-distance electrical and calcium signaling in plants. Annu Rev Plant Biol. 67:287-307.

Coca M, Segundo BS (2010) AtCPK1 calcium-dependent protein kinase mediates pathogen resistance in Arabidopsis. Plant J. 63:526-40.

Costa AC, Rosa M, Megguer CA, Silva FG, Pereira FD, Otoni WC (2014) A reliable methodology for assessing the in vitro photosynthetic competence of two Brazilian savana species: Hyptis marrubioides and Hancornia speciosa. Plant Cell. Tissue and Organ Culture. 117:443-454.
Cutter EG (1986) Anatomia vegetal. Parte I Células e tecidos. (Roca: São Paulo)

De Aquino STM, dos Santos RF, Batista KD (2019) Nutritional deficiency symptoms of young 'cedro doce' plants grown under macronutrient omission. Rev Bras Eng Agr Amb. 23:264-270.

Divol F, Couch D, Conéjéro G, Roschzttardtz H, Mari S, Curie C (2013) The Arabidopsis YELLOW STRIPE LIKE4 and 6 transporters control iron release from the chloroplast. Plant Cell. 25:1040-55.

Dodd AN, Kudla J, Sanders D (2010) The language of calcium signaling. Annu Rev Plant Biol. 61:593-620.

Ferreira DF, SISVAR - Sistema de análise de variância (2010) UFLA, Lavras-MG.

Ferreira T, Rasband W (2010) O ImageJ Guia do UsuárioVersion 1,43. Disponível em: http://rsbweb.nih.gov/ij/docs/user-guide.pdf [Verified february 2019]

Gläser K, Kanawati B, Kubo T, Schmitt-Kopplin P, Grill E (2014) Exploring the Arabidopsis sulfur metabolome. Plant J. 77:3145.

Henry JB, Vann M, McCall I, Cockson P, Whipker BE (2018) Nutrient disorders of burley and flue-cured tobacco: Part 1-Macronutrient deficiencies. Crop, Forage \& Turfgrass Management. 4:1-8.

Hirai MY, Yano M, Goodenowe DB, Kanaya S, Kimura T, Awazuhara M, Arita M, Fujiwara T, Saito K (2004) Integration of transcriptomics and metabolomics for understanding of global responses to nutritional stresses in Arabidopsis thaliana. Proceedings of the National Academy of Sciences of the United States of America. 101:10205-10210.

Hoagland DR, Arnon DI (1950) The water-culture method for growing plants without soil. (University of California, College of Agriculture, Agricultural Experiment Station, California, USA)

Karnovsky MJ (1965) A formaldehyde-glutaraldehyde fixative of high osmolality for use in electron microscopy. J Cell Biol. 27:137-138.

Keunen E, Remans T, Bohler S, Vangronveld J, Cuypers A (2011) Metal-induced oxidative stress and plant mitochondria. Int J Mol Sci. 12:6894-6918.

Lavres Junior J, Reis AR, Rossi ML, Cabral CP, Nogueira NL, Malavolta E (2010) Changes in the ultrastructure of soybean cultivars in response to manganese supply in solution culture. Sci Agr. 67:287-294.

Lersten NR (1967) An annotated bibliography of botanical clearing methods. lowa State Journal of Science. 41:481-486.

Maathuis JM (2009) Physiological functions of mineral macronutrients. Curr Opin Plant Biol. 12:250-258. doi:10.1016/j.pbi.2009.04.003

Malakouti MJ (2008) The effect of micronutrients in ensuring efficient use of macronutrients. Turk J Agric For. 32:215-220.

Marschner P (2012) Marschner's mineral nutrition of higher plants. (London, UK: Academic Press)

Mattiello EM, Ruiz HA, Neves JCL, Ventrella MC, Araújo WL (2015) Zinc deficiency affects physiological and anatomical characteristics in maize leaves. J Plant Physiol. 183:138-143. Miranda RP, Pietroski M, Matos FB, Seben Junior GF, Caione G (2017) Nitrogen, potassium, calcium and sulfur omission in grass Convert. Comunicata Scientiae. 8:452-458. 
Nikiforova VJ, Kopka J, Tolstikov V, Fiehn O, Hopkins L, Hawkesford MJ, Hesse H, Hoefgen R (2005) Systems rebalancing of metabolism in response to sulfur deprivation, as revealed by metabolome analysis of Arabidopsis plants. Plant Physiol. 138:304-318.

O'Brien TP, Feder N, McCully ME (1964) Coloração policromático das paredes celulares da planta por azul de toluidina O. Protoplasma. 59:368-373.

Orlov SN, Aksentsev SL, Kotelevtsev SV (2005) Extracellular calcium is required for the maintenance of plasma membrane integrity in nucleated cells. Cell Calcium. 38:5357.

Osório J, Osório ML, Correia PJ, Varennes A, Pestana M (2014) Chlorophyll fluorescence imaging as a tool to understand the impact of iron deficiency and resupply on photosynthetic performance of strawberry plants. Sci Hortic. 165:148-155.

Ranty B, Aldon D, Cotelle V, Galaud J-P, Thuleau P, Mazars C (2016) Calcium sensors as key hubs in plant responses to biotic and abiotic stresses. Front Plant Sci. 7:327.

Roosta HR, Estaji A, Niknam F (2018) Effect of iron, zinc and manganese shortage-induced change on photosynthetic pigments, some osmoregulators and chlorophyll fluorescence parameters in lettuce. Photosynthetica. 56:606615.

Samborska IA, Kalaji HM, Sieczko L, Borucki W, Mazur R, Kouzmanova M, Goltsev V (2019) Can just one-second measurement of chlorophylla fluorescence be used to predict sulphur deficiency in radish (Raphanus sativus L. sativus) plants? Curr Plant Biol.

Santiago FEM, Santiago FLA, Filho JFL, Ratke RF (2018) Plant growth and symptomatology of macronutrient deficiencies in cowpea plants. Comunicata Scientiae. 9:503-508.

Santos EF, Zanchim BJ, Campos AG, Garrone RF, Lavres Junior J (2013) Photosynthesis rate, chlorophyll content and initial development of physic nut without micronutrient fertilization. Revista Brasileira de Ciência do Solo. 37:13341342.

Shen JR (2015) The structure of photosystem II and the mechanism of water oxidation in photosynthesis. Annu Rev Plant Biol. 66:23-48.
Silva MPS, Freitas MSM, Santos PC, Carvalho AJC, Jorge TS (2019) Capsicum annuum var. annuum under macronutrients and boron deficiencies: Leaf content and visual symptoms. J Plant Nutr. 42:417-427.

Siose TK, Kader MA, Tulin AB (2017) Determination of limiting nutrient to Sweetpotato (L.) growth on Samoa oxisol using a Ipomoea batatas nutrient omission technique. Ann Trop Res. 39:105-119.

Socha AL, Guerinot ML (2014) Mn-euvering manganese: the role of transporter gene family members in manganese uptake and mobilization in plants. Front Plant Sci. 5:106.

Sousa ERB, Camilo YMV, Vera R (2018) Cagaita - Eugenia dysenterica. In Exotic Fruits. (Eds. S Rodrigues, EO Silva, ES Brito), pp. 77-83. (Academic Press: London).

Souza GA de, Pinho PJ, Bastos ARR, Coelho LC, Botrel ÉP, Carvalho JG (2015). Boron simple and multiple omissions with $\mathrm{Ca}, \mathrm{Fe}, \mathrm{Mn}$ and $\mathrm{Zn}$ in castor bean plants (Ricinus communis). Revista Agrarian. 8:287-295.

Sutradhar AK, Kaiser DE, Behnken LM (2017) Soybean response to broadcast application of boron, chlorine, manganese, and zinc. Agronomy Journal. 109:1048-1059.

Tisujimoto Y, Yamamoto Y, Hayashi K, Zakaria Al, Inusah Y, Hatta T, Fosu M, Sakagami J-I (2013) Topographic distribution of the soil total carbon content and sulfur deficiency for rice cultivation in a floodplain ecosystem of the Northern region of Ghana. Field Crops Res. 152: 74-82.

Wang L, Tsuda K, Sato M, Cohen JD, Katagiri F, Glazebrook $\mathrm{J}$ (2009) Arabidopsis CaM binding protein CBP60g contributes to MAMP-induced SA accumulation and is involved in disease resistance against Pseudomonas syringae. PLoS Pathogens. 5: e1000301.

White PJ, Broadley MR (2003) Calcium in plants. Ann Bot. 92:487-511.

Welburn AR (1994). The spectral determination of chlorophylls $a$ and $b$, as well as total carotenoids, using various solvents with spectrophotometers of different resolution. J Plant Physiol. 144:307-313.

Wong M (2005) Visual symptoms of plant nutrient deficiencies in nursery and landscape plants. Soil and Crop Management, 1-4.

Young M, Kanashiro S, Jocys T, Tavares AR (2018) Silver vase bromeliad: Plant growth and mineral nutrition under macronutrients omission. Sci Hortic. 234:318-322. 